\title{
Complete adherence to antenatal care guideline during the first visit and antepartum complications in public health facilities: a prospective cohort study in Northwest Ethiopia
}

Tewodros Seyoum ( $\nabla$ tedysha@gmail.com)

University of Gondar College of Medicine and Health Sciences https://orcid.org/0000-0002-9915-6368

Mekuriaw Alemayehu

University of Gondar College of Medicine and Health Sciences

Kyllike Christensson

Karolinska Institutet

Helena Lindgren

Karolinska Institutet

\section{Research}

Keywords: Complete provider adherence, first ANC visit, antepartum complications, Ethiopia

Posted Date: June 15th, 2021

DOI: https://doi.org/10.21203/rs.3.rs-605611/v1

License: (c) (i) This work is licensed under a Creative Commons Attribution 4.0 International License. Read Full License 


\section{Abstract Background}

Adherence to a minimum level of recommended content during the first Antenatal care (ANC) is low in Ethiopia but less is known about if there is an association between the level of adherence to focused ANC guideline and pregnancy outcomes. Therefore, the goal of this study was to examine the relationship between the level of adherence to Ethiopian ANC guidelines during the first visit and maternal complications that occur during the antepartum period.

\section{Methods}

A prospective cohort study was conducted in Gondar town public health facilities from May, 2019, to January, 2020. A total of 832 pregnant women with gestational age $<28$ weeks who came for their first ANC visit were enrolled and followed until their last visit or before the commencement of labor. An 18-point checklist was used to record the level of providers' adherence. Clients who received all the components in the ANC guideline during the first visit adhered to by the provider were considered as an exposed group. A Log-binomial model was used to examine the relationship between the level of adherence to the guideline and the risk of antenatal complications. The adjusted Relative Risk (ARR) with a 95\% Confidence Interval (Cl) was reported in the final model.

\section{Result}

A total of 808 pregnant women were included in the final analysis. Complete providers' adherence was associated with a lower risk of anemia $(A R R=0.54 ; 95 \% \mathrm{Cl}: 0.31,0.94)$, but with a higher risk for Pregnancy-induced hypertension $(\mathrm{ARR}=1.71 ; 95 \% \mathrm{Cl}$ : 1.04, 2.81).

\section{Conclusions}

Complete providers' adherence to the first ANC guideline influences maternal complications during antepartum period. Therefore, improving the level of adherence by the provider to the ANC guideline during the first visit is very important.

\section{Background}

ANC remain to be an effective intervention in reducing the risk of pregnancy-related complications [1]. World Health Organization (WHO) had previously recommended at least four visits and more recently, the standard ANC guideline has been implemented at least eight ANC contacts [1, 2]. The eight-contact ANC guidelines are used in a few countries but at a level that must be seen as all too low [3,4].

The importance of ANC is not questionable, however, the number of visits, the quality of care, and the relationship with perinatal outcomes have been areas of research and controversy $[5,6]$. Although coverage measures are widely used in maternal health, these measures often focus on service contacts as opposed to the interventions delivered during those contacts [7]. There have been some studies on ANC adequacy measured by the number and timing of visits that have been equivocal to ANC's ability to improve pregnancy outcomes and demonstrated inconsistent relationships [8-10].

Unlike other visits, the first ANC visit is unique in its intent. A timely first ANC visit creates an opportunity for a woman to connect with formal health services and provides the possibility that early screening of pregnant women can identify those who will require specialized care [11]. The first visit also helps the provider identify those pregnant women who are very likely to experience unfavorable obstetrical outcomes like antepartum hemorrhage [12]. The first visit is the proper time to provide preventive interventions, for example providing iron tablets and explaining why and also providing counseling if there are any danger signs [13]. Thus, health care providers need to adhere to the ANC guideline to provide a minimum level of care to all pregnant women during the first visit. Yet adherence to ANC guidelines is low in low and middle-income countries [14-16] and this might be expected to result in otherwise avoidable poor obstetric outcomes [17]

In 2017 WHO report, Ethiopia was one of the Sub-Saharan African countries with the highest maternal mortality, estimated at 401 per 100000 live births [18]. Hemorrhage (41.3\%), hypertensive disorders of pregnancy (18.6\%), and anemia (17.5\%) were the leading causes of maternal mortality in Ethiopia. Deaths from these complications occurred during the antepartum period [19]. Since no studies have been made in Ethiopia, the possible effect of good ANC practice in reducing the level of these kinds of maternal mortality is not yet known. Reducing maternal mortality and improving maternal health is a top priority of the Ethiopian health authorities by increasing the coverage of focused ANC with at least four visits [20]. As one of the low-income countries, Ethiopia has accepted and been implementing focused ANC [21]. 
The history of working with ANC guideline is not new in Ethiopia. However, the guideline is vague with no clear independent document used as focused ANC guideline [22]. This guideline is embedded into the Ethiopian national obstetric protocol and incorporated in basic emergency obstetric newborn care training manuals $[23,24]$. The provision of ANC services in urban areas of Ethiopia is the joint responsibility of midwives and obstetricians [25].

To date, only $74 \%$ of pregnant women in Ethiopia had attended at least one ANC visit, and even those who receive it do not get quality services due to providers' inability to adhere to ANC guideline $[26,27]$. A local study done in Gondar town indicated that only $32 \%$ of women received complete providers' adherence to national ANC guideline during the first visit [28]. Lack of in-service training and unavailability of printed ANC guidelines were the main reason given by providers for not being able to follow the ANC guideline [29]. But less is known about if there is an association between complete adherence to focused ANC guideline and pregnancy outcomes. Therefore, the goal of this study was to examine the relationship between the level of adherence to Ethiopian ANC guidelines during the first visit and maternal complications that occur during the antepartum period in Gondar town public health facilities.

\section{Methods And Materials}

\section{Study design, setting and period}

A facility-based prospective cohort study was conducted from May 12, 2019, to January 30, 2020. The study was conducted at four selected public health facilities of Gondar town; the University of Gondar comprehensive specialized hospital, Poly health center, Azezo health center, and Maraki health center. Details of the study setting are described elsewhere [16].

\section{Population and recruitment of study participants}

All pregnant women who came for their first ANC visit at the selected public health facilities during the data collection period were considered as eligible for the study. Then, beginning from the first ANC visit to either the last visit or the commencement of labor, they were all followed prospectively. The pregnant women included in the study were followed if they were age 18 or older, had a gestational age of 28 weeks or less, were permanent residents in the study area, and were prepared to make regular ANC visits. Clients who had complications at the time of enrollment were excluded.

\section{Exposed group}

Pregnant women who received complete adherence to focused ANC guideline during the first visit.

\section{Unexposed group}

Pregnant women who received incomplete adherence to focused ANC guideline during the first visit.

\section{Sample size and sampling procedure}

Sample size estimation was calculated using Epi Info version 7 software taking into account the following statistical assumptions: confidence level of $95 \%$ (2-sided), power of $80 \%$, exposed to the non-exposed ratio of 1:2, the overall incidence (non-exposed group) for any pregnancy, delivery or postpartum complication was $68.6 \%$, taken from a study conducted in Ghana[17]. We assumed that the incidence of antenatal complications would be decreased by $15.4 \%$ by completely adhering to ANC guideline during the first visit, making the overall incidence of complications 53.2\% amongst the exposed group (complete adherence). This study also considered the design effect of 2 and lost follow-up and non-response rate of $10 \%$. The final sample size required for the study was 832 women, of these, 277 were exposed and 555 non-exposed participants. The details of the sampling procedure are described elsewhere [16].

\section{Data collection process}

Both an observation checklist and a structured questionnaire were prepared. The observation checklist with 18-items was developed based on the Ethiopian ANC protocol of the first visit. The checklist comprised history taking, physical examination, routine tests, and counseling/ provision of information.

Direct observation was done while the providers were doing the first ANC service. Exit face-to-face interview was also done. Finally, participants were classified as exposed or non-exposed and then followed prospectively until their last visit or before the commencement of labor. Based on the recommendation of the focused ANC schedule, pregnant women were followed, with the second visit at 28 and above weeks and third visit at 32 weeks, and the fourth visit at 36 weeks. Another structured 9-point checklist, extracted from the focused ANC guideline, was used during the subsequent ANC visits to observe how counseling was conducted. The observed counseling services include iron and folic acid supplementation, tetanus immunization, how to recognize danger signs, what to do if danger signs were present, and where to get support, HIV testing and counseling, the value of skilled attendance at birth, nutrition, de-worming, birth preparedness and complication readiness plan, and risks of using 
tobacco and alcohol during pregnancy. The trained providers, such as midwives and gynecologists who are working in the ANC rooms were ascertained antenatal complications. Both maternal medical records and integrated ANC charts of subsequent antenatal visits were reviewed to abstract antenatal complications and recorded in the checklist prepared for this purpose. During recruitment, participants' telephone numbers were registered. For those clients who didn't avail themselves in the scheduled ANC visit, they were notified via a phone call. Those who could not be reached by any of these means were considered as lost to follow-up. Both the data collectors and supervisors were midwives and they were not employed in the health facilities under the study. Three days training was given on the data collection instrument, how to approach and observe the service provision to ensure the feasibility of replication of the measurements by comparable workers. For example, gestational age can be estimated from clinical information when ultrasound is not available.

\section{Variables}

The outcome variables of the study were selected antenatal complications. These include anemia, pregnancy induced-hypertension (including pre-eclampsia and eclampsia), antepartum hemorrhage, urinary tract infection, gestational Diabetic Mellitus and premature rupture of membrane. The composite antenatal complication was defined as the presence of at least one of the above complications.

The level of providers' adherence to the Ethiopian focused ANC guideline during the first visit was the primary exposure variable. The other covariate variables include the type of facility, the client's socio-demographics, and obstetric factors.

\section{Measurement of variables}

\section{Measuring adherence}

Provider adherence levels on the first ANC guideline were defined as complete or incomplete. The detailed measurement of the primary exposure variable, the adherence checklist, and the scoring criteria are described elsewhere [16].

\section{Antenatal counseling}

The extent of the counseling service during pregnancy was measured by monitoring nine composite variables. When one component of counseling service was given at all visits, it was coded as 1 otherwise 0 . Composite counseling service was defined as the service given to pregnant women who got counseling specified by at least one or more variables out of the nine counseling variables [27].

\section{Anemia}

Anemia was defined as the occurrence of a hemoglobin level of less than $11 \mathrm{~g} / \mathrm{dL}$ as identified after the first visit [1].

\section{Pregnancy-Induced Hypertension(PIH)}

$\mathrm{PIH}$ was determined by measuring systolic blood pressure $\geq 140 \mathrm{mmHg}$ and/or diastolic blood pressure $\geq 90 \mathrm{mmHg}$ after $20 \mathrm{weeks}$ of pregnancy with or without proteinuria or with tonic-colonic convulsion [30].

\section{Antepartum Hemorrhage (APH)}

APH was defined as bleeding from or into the genital tract, occurring during the third trimester of pregnancy and before the birth of the baby [30].

Gestational Diabetic Mellitus (GDM): The diagnosis of GDM was made when one or more of the following values of plasma glucose level was met (fasting: $\geq 92 \mathrm{mg} / \mathrm{dL}, 1 \mathrm{~h}: \geq 180 \mathrm{mg} / \mathrm{dL} ; 2 \mathrm{~h}: \geq 153 \mathrm{mg} / \mathrm{dL}$ ) after 24 weeks of pregnancy [31].

\section{Urinary Tract Infection (UTI)}

UTC was identified by the presence of microorganisms (predominantly bacteria) in urine along with urinary symptoms of dysuria, frequency, urgency, and occasionally supra-pubic tenderness during pregnancy [30].

\section{Spontaneous abortion}

Spontaneous abortion was recognized by identification of vaginal bleeding through the genital tract before 28 weeks of gestation [23].

\section{Premature Rupture of the Membrane (PROM)}

PROM was identified by recognition of rupture of membranes before the onset of labor [23].

\section{Composite antepartum complication}

The composite antepartum complication was defined as the presence of at least one of the above complications. 


\section{Statistical analysis}

Data analysis was carried out by STATA version 14 for analysis. Descriptive statistics were used to present the data in terms such as frequencies and percentages. A Log-binomial model was used to examine the possible relationship between complete provider adherence to the Ethiopian ANC guidelines during the first visit and the risk of antenatal complications. Both the covariates and the main exposure variable were fitted into the multivariable log-binomial model. Multicollinearity between variables was assessed using variance inflation factors (VIF), which was < 10 for all variables. The risk of each antenatal complication was described using the Crude Relative Risks (CRRs) and ARRs with the corresponding $95 \%$ Cls. Finally, a p-value $<0.05$ was considered to identify statistically significant variables for each antenatal complication.

\section{Result}

\section{Background characteristics of study participants}

Among the total of 832 eligible women, 808 (97.1\%) of them completed their follow-up. The reasons for loss to follow-up were self-referral to other health facilities and permanent change in the workplace. There were no statistically significant differences at baseline among women who completed the process and those who were lost to follow-up.

Among women, who completed the follow-up, 112(13.9\%) and 29(3.6\%) were in the age group of 18-19 years (teenage pregnancy) and with age $>35$ years (elderly pregnancy) respectively with a mean ( \pm SD) age of $25.92 \pm 1.93$ years. Seven hundred ninety-two pregnant women ( $98 \%$ ) came from the urban area. Five-hundred seventy (70.5\%) women were booked for their first visit after 16 weeks of gestation and 234 (28.9\%) had $2-4$ visits. One-fifth (21.8) of study participants had a history of previous pregnancy complications. Details of the socio-demographic and obstetric characteristics of the participants in the exposed and non-exposed groups are given in Tables 1 and 2.

Table 1

Socio-demographic characteristics of study participants among exposed and unexposed groups in Gondar town public health facilities, 2020(n

\begin{tabular}{|c|c|c|c|c|c|}
\hline \multicolumn{2}{|l|}{ Socio-demographic variables } & \multirow{2}{*}{$\begin{array}{l}\text { Frequency (\%) of total } \\
\text { participants } \\
n=808\end{array}$} & \multirow{2}{*}{$\begin{array}{l}\text { Frequency (\%) of the } \\
\text { exposed group } \\
n=261\end{array}$} & \multirow{2}{*}{$\begin{array}{l}\text { Frequency (\%) of the } \\
\text { unexposed group } \\
n=547\end{array}$} & \multirow[t]{2}{*}{$\begin{array}{l}P \text { - } \\
\text { value }\end{array}$} \\
\hline & & & & & \\
\hline \multirow{2}{*}{$\begin{array}{l}\text { Type of health facility ANC } \\
\text { attended }\end{array}$} & Hospital & $421(52.1)$ & $132(50.6)$ & $289(52.8)$ & \multirow[t]{2}{*}{0.56} \\
\hline & $\begin{array}{l}\text { Health } \\
\text { centers }\end{array}$ & $387(47.9)$ & $129(49.4)$ & $258(47.2)$ & \\
\hline \multirow[t]{3}{*}{ Age (in years) } & $<20$ & $112(13.9)$ & $20(11.1)$ & $83(15.2)$ & \multirow[t]{3}{*}{0.28} \\
\hline & $20-35$ & $667(82.5)$ & $223(85.4)$ & $444(81.2)$ & \\
\hline & $>35$ & $29(3.6)$ & $9(3.4)$ & $20(3.7)$ & \\
\hline Residence & Urban & $792(98.0)$ & 255(97.7) & $537(98.2)$ & 0.65 \\
\hline \multirow[t]{3}{*}{ Religion } & Orthodox & $740(91.6)$ & 233(89.3) & $507(92.7)$ & \multirow[t]{3}{*}{0.26} \\
\hline & Muslim & $58(7.2)$ & $24(9.2)$ & $34(6.2)$ & \\
\hline & Others & $10(1.2)$ & $4(1.5)$ & $6(1.1)$ & \\
\hline Marital status & Married & $785(97.2)$ & 257 (98.5) & $528(96.5)$ & 0.09 \\
\hline \multirow[t]{4}{*}{ Educational level } & None & $138(17.1)$ & $53(20.3)$ & 85 (15.5) & \multirow[t]{4}{*}{0.11} \\
\hline & Primary & $200(24.8)$ & $57(21.8)$ & $143(26.1)$ & \\
\hline & Secondary & $246(30.4)$ & $74(28.4)$ & $172(31.4)$ & \\
\hline & Tertiary & $224(27.7)$ & $77(29.5)$ & $147(26.9)$ & \\
\hline Employment & Yes & $188(23.3)$ & $68(26.1)$ & $120(21.9)$ & 0.19 \\
\hline
\end{tabular}


Table 2

Obstetric characteristics of study participants among exposed and unexposed groups in Gondar town public health facilities, 2020 ( $n=808$ )

\begin{tabular}{|c|c|c|c|c|c|}
\hline \multirow[t]{2}{*}{ Obstetric variables } & & $\begin{array}{l}\text { Frequency (\%) of total } \\
\text { participants }\end{array}$ & $\begin{array}{l}\text { Frequency (\%) of the } \\
\text { exposed group }\end{array}$ & $\begin{array}{l}\text { Frequency (\%) of the } \\
\text { unexposed group }\end{array}$ & $\begin{array}{l}P- \\
\text { value }\end{array}$ \\
\hline & & $n=808$ & $n=261$ & $n=547$ & \\
\hline \multirow[t]{2}{*}{ Time of booking } & $\begin{array}{l}\text { Early booking (< } \\
16 \text { weeks) }\end{array}$ & $238(29.5)$ & $64(24.5)$ & 174 (31.8) & 0.034 \\
\hline & $\begin{array}{l}\text { Late booking }(\geq \\
16 \text { weeks) }\end{array}$ & $570(70.5)$ & $197(75.5)$ & $373(68.2)$ & \\
\hline \multirow[t]{2}{*}{ Gravidity } & Primigravidea & $316(39.1)$ & 98 (37.5) & 218 (39.9) & 0.53 \\
\hline & Multigravidea & $492(60.9)$ & $163(62.5)$ & $329(60.1)$ & \\
\hline \multirow[t]{4}{*}{ Parity } & 0 & $358(44.3)$ & $112(42.9)$ & $246(45.0)$ & 0.89 \\
\hline & $1-2$ & $371(45.9)$ & $123(47.1)$ & $248(45.3)$ & \\
\hline & $3-4$ & $65(8.0)$ & $22(8.4)$ & $43(7.9)$ & \\
\hline & $>4$ & $14(1.7)$ & $4(1.5)$ & 10 (1.8) & \\
\hline \multirow{2}{*}{$\begin{array}{l}\text { Previous history of } \\
\text { pregnancy complications }\end{array}$} & Yes & $107(21.8)$ & $43(26.7)$ & 64 (19.5) & 0.05 \\
\hline & No & $383(78.2)$ & $118(73.3)$ & $265(80.5)$ & \\
\hline \multirow{3}{*}{$\begin{array}{l}\text { Birth to pregnancy interval } \\
\text { (in month) }\end{array}$} & Short( $\leq 24)$ & $117(26)$ & $40(27.0)$ & 77 (25.5) & 0.92 \\
\hline & $\begin{array}{l}\text { Recommended } \\
(24-48)\end{array}$ & $172(38.2)$ & 55 (37.2) & 117 (38.7) & \\
\hline & Long(>48) & $161(35.8)$ & $53(35.8)$ & 108 (35.8) & \\
\hline \multirow[t]{2}{*}{ Intention of pregnancy } & Planned & 737 (91.2) & 234 (89.7) & 503 (92.0) & 0.28 \\
\hline & Unplanned & $71(8.8)$ & $27(10.3)$ & $44(8.0)$ & \\
\hline \multirow[t]{2}{*}{$\begin{array}{l}\text { Number of ANC visit } \\
\text { attended }\end{array}$} & $\leq 4$ visits & 234(29.0) & $73(27.9)$ & 161(29.4) & 0.66 \\
\hline & $>4$ visits & $574(71.0)$ & 188(72.0) & $386(70.6)$ & \\
\hline
\end{tabular}

\section{Counseling services during pregnancy}

Counseling services that could take into account nine different components of the guidelines were observed throughout pregnancy. The proportion of pregnant women who received counseling on at least one of the nine components at all visits was $88.7 \%$ [95\% $\mathrm{Cl}(86.3,90.7 \%)$. Five hundred fifty-eight (69.1\%) pregnant women were counseled in all visits about iron and folic acid supplementation. Six hundred eighty-nine $(85.3 \%)$ and $647(80.1 \%)$ of the women were counseled on how to recognize danger signs, what to do, and where to get help during the 2 nd and 4th visits respectively. Nine (1.1\%) of study participants received HIV testing and counseling service in all visits (Table 3 ). 
Table 3

Counseling services provided to pregnant women during ANC visits at public health facilities of Gondar town, 2020 ( $n=808$ )

\begin{tabular}{|lllll|}
\hline Observed counseling services & 2nd visit & 3rd visit & 4th visit & All visits (2-4) $\mathbf{n}(\%)$ \\
\hline Iron and folate supplementation. & $\mathbf{n}(\%)$ & $\mathbf{n}(\%)$ & $\mathbf{n}(\%)$ & $558(69.1)$ \\
\hline Immunization against tetanus & $719(89.0)$ & $664(82.2)$ & $586(72.5)$ & $54(5.3)$ \\
\hline How to recognize danger signs, what to do, and where to get help & $689(85.3)$ & $659(81.6)$ & $647(80.1)$ & $494(61.1)$ \\
\hline HIV testing and counselling & $166(20.5)$ & $88(10.9)$ & $58(7.2)$ & $9(1.1)$ \\
\hline The benefit of skilled attendance at birth & $170(21.0)$ & $191(23.6)$ & $300(37.1)$ & $32(4.0)$ \\
\hline Good nutrition and the importance of rest & $523(64.7)$ & $480(59.4)$ & $440(54.5)$ & $245(30.3)$ \\
\hline De-worming with mebendazole & $47(5.8)$ & $208(25.7)$ & $118(14.6)$ & $11(1.4)$ \\
\hline Birth preparedness' and complication readiness plan & $191(23.6)$ & $334(41.3)$ & $518(64.1)$ & $75(9.3)$ \\
\hline Risks of using tobacco and alcohol, & $64(7.9)$ & $33(4.1)$ & $34(4.2)$ & $5(0.6)$ \\
\hline
\end{tabular}

\section{Incidence of antepartum complications}

Overall, two hundred forty-five (30.2\%) of the participants developed antepartum complications. Of these, the incidence of antepartum complications among mothers who received complete providers' to ANC guideline during the first visit was $28.6 \%$. The incidence of anemia among mothers who received either complete or incomplete adherence providers' was $6.1 \%$ and $10.8 \%$ respectively. The incidence of GDM among the exposed (1.2\%) and unexposed group (1.3\%) is almost the same (Fig. 1).

\section{The relationship between complete providers' adherence to Ethiopian ANC guideline during the first visit and antepartum complications}

Both Bi-variable and multivariable Log-binomial regression analyses were done for selected antepartum complications like anemia, $\mathrm{PIH}$, APH, PROM, UTI, and composite antepartum complication. But GDM and abortion were excluded from regression analysis due to the small number of cells in both groups. After adjusting for confounding variables, the results of multivariable log-binomial model showed that complete provider adherence to the guideline was associated with a lower risk of anemia (ARR = 0.54; 95\% Cl: 0.31, 0.94) and PROM (ARR= 0.38; 95\% Cl: 0.16, 0.92), but higher for PIH (ARR = 1.71; 95\% Cl: 1.04, 2.81). However, there were no significant differences in the risk of composite antenatal complications (ARR = 0.93; 95\% Cl: 0.73, 1, 19), APH (ARR=0.90; 95\% Cl: 0.43, 1.89), and UTI (ARR = 1.10; 95\% Cl: 0.55, 2.20) between the two groups (Table 5). A more details of Bi-variable analysis for each antepartum complication with all variables is shown in additional file 1 (Table 4).

Table 4: Bivariable association between independent variables and selected antepartum complications among study participants in Gondar town public health facilities, Northwest Ethiopia, $2020(n=808)$

*stands for Crude P-value $<0.25$

Table 5

Summary of Log-binomial regression analysis showing the relationship between women who received complete adherence to first Ethiopian ANC guideline and the risk of antepartum complications in Gondar town public health facilities, Northwest Ethiopia, 2020 ( $n=808$ ).

\begin{tabular}{|c|c|c|c|c|}
\hline Complication & CRR(95\% Cl) & p-value & $\operatorname{ARR}(95 \% \mathrm{Cl})$ * & p-value \\
\hline Anemia & $0.56(0.33,0.96)$ & 0.038 & $0.54(0.31,0.94)$ & 0.03 \\
\hline $\mathrm{PIH}$ & $1.33(0.88,2.00)$ & 0.17 & $01.71(1.04,2.81)$ & 0.034 \\
\hline $\mathrm{APH}$ & $0.91(0.45,182)$ & 0.79 & $0.90(0.43,1,89)$ & 0.79 \\
\hline UTI & $0.96(0.49,1.88)$ & 0.92 & $1.10(0.55,2.20)$ & 0.76 \\
\hline \multirow[t]{2}{*}{ PROM } & 0.38 & 0.03 & $0.38(0.16,0.92)$ & 0.032 \\
\hline & $(0.16,0.92)$ & & & \\
\hline Composite antenatal complication & $0.92(0.73,1.16)$ & 0.50 & $0.93(0.73,1,19)$ & 0.58 \\
\hline
\end{tabular}




\begin{tabular}{|c|c|c|c|c|c|}
\hline \multirow[t]{3}{*}{ Explanatory Variables } & \multicolumn{5}{|c|}{ Antepartum complications } \\
\hline & Anemia & $\mathrm{PIH}$ & APH & UTI & PROM \\
\hline & $\mathrm{RR}(95 \% \mathrm{Cl})$ & $\mathrm{RR}(95 \% \mathrm{Cl})$ & $\mathrm{RR}(95 \% \mathrm{Cl})$ & $\mathrm{RR}(95 \% \mathrm{Cl})$ & $(95 \% \mathrm{Cl})$ \\
\hline Received complete adherence & $0.56(0.33,0.96)^{\star}$ & $1.33(0.88,2.01)^{\star}$ & $0.91(0,45,1.82)$ & $0.96(0.49,1.88)$ & $0.38(0.16,0.92)^{\star}$ \\
\hline \multicolumn{6}{|l|}{ Age (in years) } \\
\hline$<20$ & 1 & $0.77(0.31,1.96)$ & 1 & 1 & 1 \\
\hline $20-35$ & $1.38(0.68,2.80)$ & $0.56(0.24,1.29)^{\star}$ & $0.81(0.34,1.92)$ & $0.83(0.35,1.97)$ & $1.77(0,55,5.68)$ \\
\hline$>35$ & $0.48(0.06,3.71$ & 1 & $0.69(0.86,5.50$ & $1.28(0.27,6.04)$ & $2.69(0.47,15.29)^{\star}$ \\
\hline \multicolumn{6}{|l|}{ Educational level } \\
\hline None & 1 & 1 & 1 & 1 & 1 \\
\hline Primary & $1.38(0.69,2.75)$ & $0.76(0.42,1.36)$ & $0.68(0.26,1.78)$ & $2.41(0.81,7.18)^{\star}$ & $1.22(0.42,3.57)$ \\
\hline Secondary & $0.81(0.38,1.70)$ & $0.64(0.36,1.15)^{\star}$ & $0.62(0.26,1.78)$ & $1.29(0.39,4.02)$ & $1.07(0.37,3.08)$ \\
\hline Tertiary & $1.45(0.74,2.85)^{\star}$ & $0.74(0.42,1.31)$ & $0.83(0.34,2.03)$ & $1.69(0.55,5.21$ & $1.65(0.60,4.48)$ \\
\hline \multicolumn{6}{|l|}{ Employment } \\
\hline Yes & 1 & 1 & 1 & 1 & 1 \\
\hline No & $0.60(0.38,0.95)^{\star}$ & $1.12(0.68,1.84)$ & $1.25(0.55,2.80)$ & $1.34(0.60,2.99)$ & $0.85(0.42,1.72)$ \\
\hline \multicolumn{6}{|l|}{ Time of booking } \\
\hline Early & 1 & 1 & 1 & 1 & 1 \\
\hline Late & $0.62(0.40,0.96)^{\star}$ & $1.09(0.67,1.66)^{\star}$ & $0.83(0.39,1.75$ & $0.51(0.27,0.96)^{\star}$ & $0.71(0.37,1.36)^{\star}$ \\
\hline Previous pregnancy complication(yes) & $1.12(0.61,2.06)$ & $1.20(0.67,2.15)$ & $1.04(0.41,2.63)$ & $0.02(0.02,0.06)$ & $0.55(0.17,1.76)$ \\
\hline \multicolumn{6}{|l|}{ Parity (number) } \\
\hline 0 & 1 & 1 & 1 & 1 & 1 \\
\hline $1-2$ & $1.05(0.66,1.66)$ & $1.16(0.75,1.79)$ & $1.28(0.612 .67)$ & $0.67(0.34,1.31)^{\star}$ & $1.07(0.55,2.07)$ \\
\hline $3-4$ & $1.20(0.55,2.61)$ & $1.29(0.67,3.27)$ & $1.35(0.39,4.66)$ & $0.55(0.13,2.29)$ & $0.69(0.16,2.93)$ \\
\hline$>4$ & $0.79(0.11,5.43)$ & $1.50(0.40,5.74)$ & $7.71(3.02,19.67)^{\star}$ & $2.55(0.66,9.88)^{\star}$ & $2.38(0.59,9.57)^{\star}$ \\
\hline \multicolumn{6}{|l|}{ Place of ANC attendance } \\
\hline Hospital & $0.68(0.43,1.07)^{\star}$ & $1.76(1.05,2.96)^{\star}$ & $1.76(0.86,3.59)^{\star}$ & $0.38(0.19,0.77)^{\star}$ & $0.88(0.47,1.64)$ \\
\hline Health center & 1 & 1 & 1 & 1 & 1 \\
\hline \multicolumn{6}{|l|}{ Number of ANC visits attended } \\
\hline 4 visits & 1 & 1 & 1 & 1 & 1 \\
\hline$>4$ visits & $1.2(0.73,1.97)$ & $0.55(0.37,0.82)^{\star}$ & $0.70(0.42,1.98)^{\star}$ & $1.14(0.56,2.31)$ & $1.16(0.56,2.42)$ \\
\hline \multicolumn{6}{|l|}{ Received antenatal counseling } \\
\hline Yes & $1.45(0.65,3.26)$ & $0.64(0.37,1.09)^{\star}$ & $0.74(0.29,1.86)$ & $1.07(0.39,2.97)$ & $2.05(0.50,8.35)$ \\
\hline No & 1 & 1 & 1 & 1 & 1 \\
\hline
\end{tabular}

\section{Discussion}

This study contributes to the body of knowledge on the relationship between the level of provider adherence to the Ethiopian ANC guidelines and the incidence of antepartum maternal complications. Our findings demonstrated that complete provider adherence to the ANC guidelines during the first visit was associated with a lower risk of anemia in the mothers, but a higher risk for PIH.

During the antepartum period, over $26 \%$ of the study participants in the current study had at least one type of complication. Among these complications, the incidence of anemia was the highest (9.1\%), and the incidence increased as the gestational age increased. In a country where 
hemorrhage is the leading cause of maternal deaths [19], this is troubling since anemia will affect the capacity of the woman to adequately compensate physiologically in case of bleeding during childbirth. The incidence of anemia among the subjects in the present study was, however, much lower than the incidence reported in other studies conducted in Ethiopia [32-34] and much lower compared to the incidence in a study done in Ghana [17]. It is reasonable to believe that universal free prenatal iron supplementation could result in a decrease in the incidence of anemia[35].In addition, the women in the present study, unlike those in many other studies, were all urban residents. Urban women tend to have better access to information about basic pregnancy care.

Although $93 \%$ of the participants in our baseline study were prescribed iron tablets when they entered the study, only one of three began to take these at gestational week 16 or before [16]. This was because of most women reported late for the first ANC. This surprised us because we had assumed that urban residents would find it perhaps easier to attend on time than would women living in other settings. We did not attempt to ascertain the reasons for not attending at the assigned time. Late arrival led to late prescription and taking of iron and folic acid tablets. It is clear that in accordance with WHO recommendations, programs must be strengthen to insure that iron tablets and folic acid are prescribed and provided for pregnant women and taken as early as possible during pregnancy [1].

Secondly, we found that pregnant women whose providers adhered completely to the Ethiopian ANC guidelines during their first visit were at a lower risk of anemia by $46 \%$. The plausible explanation for the reduction of anemia among these women is that the provider made clear to them that they were to take the prescribed iron tablets and folic acid. Another contributing factor was that the counselors explained how to take the iron tablets and how to minimize any possible side effects of these medications so that the women would take them on schedule until they gave birth. Orally administered iron can cause nausea and dyspepsia, and the level of these side-effects seems to be linked to the amount of iron absorbed [36]. Therefore, the counselor must explain to each woman how to minimize side effects. In the current study, $69.1 \%$ of pregnant women received counseling service on iron supplementation continuously from the first ANC visit until their last visit. Our current study finding is consistent with findings in other studies done in Ghana [17]. The incidence of anemia after first visit among women who received either complete or incomplete provider's adherence to ANC guideline during the first visit was $14.9 \%$ and $16.1 \%$ respectively. The agreement between our study findings and those in the study done in Ghana could be due to similarities in the study setting, nature of study design and use of the same ANC guideline adapted from WHO recommendations. The study done in Ghana was a cohort study conducted in 11 health facilities in the Greater Accra region.

Though PIH is one of the unpredictable maternal complication [37], it is preventable through effective ANC screening to identify the onset of PIH before it can become severe [38]. Yet paradoxically, the findings from the present study revealed that women whose providers adhered completely to the ANC guidelines during the first visit were found to have a higher risk of PIH. This finding is consistent with other research finding conducted in Saudi Arabia[39].In Both studies, it is possible to explain the positive association between exposure and the risk of antepartum PIH in more than one way. This is probably because it is uncertain whether early detection of pre-eclampsia will reduce the incidence of eclampsia, and preventive interventions like calcium supplementation are not completely effective in reducing the risk of pre-eclampsia [40]. Therefore, focusing on screening clients who were at risk of developing PIH could lead to detection during the first visit. The screening activities done included blood pressure measurement, urine analysis for protein, and for multigravida women asked about history of PIH [41]. According to the finding from our baseline cross-sectional study, Women with previous complications received complete adherence to a higher extent [16]. This might lead health care providers to follow clients more strictly during the antepartum period than they normally would. Finally, clients who had received complete provider adherence to the first visit ANC guideline might be well counseled about the danger signs. This would probably make clients more aware of their risks and make them more conscious of the need to come to the health facility when they saw the severity signs [42].

However, the finding of this study was incongruent with the findings of a previous study done in Ghana[17] which reported no significant association between received complete provider adherence to ANC guideline during the first visit and PIH identified during antepartum period. These differences may be attributable to different clinical reasons. In the Ghana study, PIH was ascertained from the data collected from medical records retrospectively from the facility. Complications detected during pregnancy might be underreported by the health care providers. Therefore, a strong prediction tool should be developed to screen pregnant women who are at high risk of developing pre-eclampsia.

Health promotion through tailored counseling during the antepartum period was not consistently addressed in the current study. Health promotion is one of the core components of routine ANC visits that ideally would be addressed across during every ANC visit [41]. Advice on HIV testing and counseling, birth preparedness, complication readiness and advice on nutrition and risk of alcohol and smoking were the least addressed health promotion services across all visits during pregnancy. High client load and scarcity of staff were the major reasons for not adhering to health promotion services in the study public health facilities [29]. In a situation when more clients seek care per day, providers would choose which guideline items they will deal with by exempting other cervices.

The results of our study have this implication for the clinical practice. Full adherence to ANC guidelines is essential. The provider who does not adhere may fail to inform the pregnant woman about something that could result in dire consequences. Perhaps providers need to use ANC guideline to ensure that every item is dealt with during the first visit.

Page $9 / 13$ 
The prospective cohort design is the major strength of our study. The cohort design enabled us to assess the effect of single exposure on multiple antenatal complications simultaneously. In addition, we have done everything possible to minimize the magnitude of loss to follow-up during the enrollment and follow-up period. The study does, however, have limitations, which should be noted. The principal limitation of the study is that the finding of the study is not generalizable to all outcome variables. For example, only 10 and 17 participants had GDM and spontaneous abortion among all participants respectively. It would have been better to calculate the sample size for specific complications rather than combined outcomes. Finally, we are not sure that the level of provider adherence to the ANC guidelines during the first visit has a causal effect on antepartum complications with cohort study.

\section{Conclusion}

The study showed that complete provider adherence to the first-visit ANC guideline reduces at least one maternal complication during the antepartum period. A program to increase the level of provider's adherence to Ethiopian ANC guideline document should be developed. Complete adherence to the guidelines should become an essential component of antenatal care. We also believe that early antenatal care should also be encouraged amongst the population.

\section{Abbreviations}

ANC: Antenatal Care; APH: Antepartum Hemorrhage; ARR: Adjusted Relative Risk; CRRs: Crude Relative Risks; Cl: Confidence Interval; GDM: Gestational Diabetic Mellitus; PIH: Pregnancy Induced Hypertension; PROM: Premature Rupture of Membrane; UTI: Urinary Tract Infection; WHO: World Health Organization

\section{Declarations}

\section{Ethics approval and consent to participate}

The protocol has been reviewed by the Institutional ethical review board of University of the Gondar for its ethical soundness, ID: O/V/P/RCS/05/498/2018. Written informed consent was sought and obtained from each participant after the purpose and objectives of the study were explained to them before they were recruited into the study. Confidentiality was also maintained.

Consent for publication: Not applicable

\section{Availability of data and materials}

The dataset analyzed during the current study available from the corresponding author on reasonable request.

Competing interest: None declared.

\section{Funding}

The author(s) received no specific funding for this work

\section{Author contributions}

TS conceived and designed the study, analyzed the data and prepared the manuscript. MA, KC, and HL assisted in the development of the research idea, analysis, interpretation and preparation of the manuscript. All authors read and approved the final manuscript.

\section{Acknowledgments}

We would like to thank the University of Gondar for the opportunity to conduct this research. We also extend our gratitude to study participants for their willingness to be a part of the study.

\section{References}

1. Tunçalp Ó', Pena-Rosas JP, Lawrie T, Bucagu M, Oladapo OT, Portela A, et al. WHO recommendations on antenatal care for a positive pregnancy experience-going beyond survival. BJOG: An International Journal of Obstetrics Gynaecology. 2017;124(6):860-2.

2. World Health Organization. WHO antenatal care randomized trial: manual for the implementation of the new model. 2002. Avaliable from: https://apps.who.int/iris/bitstream/handle/10665/42513/WHO_RHR_01.30.pdf. Accessed, 8 April 2020.

3. Islam MM, Masud MS. Determinants of frequency and contents of antenatal care visits in Bangladesh: Assessing the extent of compliance with the WHO recommendations. PloS one. 2018;13(9):e0204752. 
4. Hlongwane TM, Bozkurt B, Barreix MC, Pattinson R, Gülmezoglu M, Vannevel V, et al. Implementing antenatal care recommendations, South Africa. Bull World Health Organ. 2021;99(3):220.

5. Dowswell T, Carroli G, Duley L, Gates S, Gülmezoglu AM, Khan-Neelofur D, et al. Alternative versus standard packages of antenatal care for low-risk pregnancy. Cochrane Database of Systematic Reviews. 2015(7). https://doi.org/10.1002/14651858.CD000934.pub3. doi: https://doi.org/10.1002/14651858.CD000934.pub3.

6. Buagbaw LMN, Darzi AJ, Richardson M, Habiba Garga K, Ongolo-Zogo P. Health system andcommunity level interventions for improving antenatal carecoverage and health outcomes. Cochrane Database Syst Rev.2015.

7. Heredia-Pi IS-ME, Darney BG, Reyes-Morales H, Lozano R. Measuring the adequacy of antenatalhealth care: a national cross-sectional study in Mexico. BullWorld Health Organ. 2016;94(6):452-61.

8. Vogel JP, Habib NA, Souza JP, Gülmezoglu AM, Dowswell T, Carroli G, et al. Antenatal care packages with reduced visits and perinatal mortality: a secondary analysis of the WHO Antenatal Care Trial. Reproductive Health. 2013;10(1):1-7.

9. Carroli G, Villar J, Piaggio G, Khan-Neelofur D, Gülmezoglu M, Mugford M, et al. WHO systematic review of randomised controlled trials of routine antenatal care. The Lancet. 2001;357(9268):1565-70.

10. Munjanja SP, Lindmark G, Nyström L. Randomised controlled trial of a reduced-visits programme of antenatal care in Harare, Zimbabwe. The Lancet. 1996;348(9024):364-9.

11. Gebreyohannes Y, Ararso D, Mengistu F, Abay S, Hadis M. Improving antenatal care services utilization in Ethiopia: an evidence-based policy brief. Int J Health Econ Policy. 2017;2:111-7.

12. Adriano B, Ingeborg J, Mercedes C, Maria Belizan, Jennifer R, Beatrice $C$, et al. Challenges and opportunities for implementing evidencebased antenatal care in Mozambique: a qualitative study. BMC Pregnancy Childbirth. 2015;15(200):7-10. doi:10.1186/s12884-015-0625-X.

13. World Health Organization. Opportunities for Africa's newborns: Antenatal Care. 2013.Report. Available: http://www.who.int/pmnch/media/publications/aonsectionIII_2.pdf. Accessed, 30 Novomber 2020.

14. Bintabara D, Nakamura K, Ntwenya J, Seino K, Mpondo BC. Adherence to standards of first-visit antenatal care among providers: A stratified analysis of Tanzanian facility-based survey for improving quality of antenatal care. PLOS ONE. 2019;14(5):e0216520.

15. Amoakoh-Coleman M, Agyepong IA, Zuithoff NP, Kayode GA, Grobbee DE, Klipstein-Grobusch K, et al. Client factors affect provider adherence to clinical guidelines during first antenatal care. PLOS ONE. 2016;11(6).

16. Seyoum T, Alemayehu M, Christensson K, et al. Client Factors Affect Provider Adherence to Guidelines during First Antenatal Care in Public Health Facilities, Ethiopia: A Multi-Center Cross-Sectional Study. Ethiop J Health Sci. 2020;30(6):903.

17. Amoakoh-Coleman M, Klipstein-Grobusch K, Agyepong IA, Kayode GA, Grobbee DE, Ansah EK. Provider adherence to first antenatal care guidelines and risk of pregnancy complications in public sector facilities: a Ghanaian cohort study. BMC Pregnancy Childbirth. 2016;16(1):1-10.

18. World Health Orgnization. Trends in maternal mortality 2000 to 2017: estimates by WHO. UNICEF, UNFPA, World Bank Group and the United Nations Population Division. Geneva. 2019. Avaliable: http://documents.worldbank.org/curated/en//Trends-in-maternal-mortality-2000-to2017-Estimates-by-WHO-UNICEF-UNFPA-World-Bank-Group-and-the-United-Nations-Population-Division,. Accessed, 14 Dec 2020.

19. Ethiopian Public Health Institute. Ethiopia - National Maternal Death Surveillance and Response System Annual Report 2010 EFY. Avaliable: https://www.afro.who.int/publications/ethiopia-national-maternal-death-surveillance-and-response-system-annual-report-2010. Acessed,5 April 2021.

20. Ministry of Health. National Reproductive Health Strategy 2006-2015, Ministry of Health, Addis Ababa, Federal Democratic Republic of Ethiopia, 2013. Avaliable from: http://www.National-Reproductive-Health-Strategy-Ethiopia.pdf. Accesed, 21 May 2021.

21. Alemayehu T, Haidar J, Habte D. Utilization of antenatal care services among teenagers in Ethiopia: a cross sectional study. Ethiopian Journal of Health Development. 2010;24(3).

22. Villadsen SF, Tersbøl BP, Negussie D, GebreMariam A, Tilahun A, Friis H, et al. Antenatal care strengthening in Jimma, Ethiopia: a mixedmethod needs assessment. Journal of environmental and public health. 2014;2014.

23. Ethiopian Federal Ministry of Health. Management protocol on selected obstetrics topics. 2010. Avaliable from: http://lifesavingcommodities.org/Management-of-Selected-Obstetric-Topics-2010-1.pdf. Accessed, 14 Nov 2020.

24. Federal Ministry of Health. Ethiopian Basic Emergency Obstetric and Newborn care training manual. 2013. Avaliable from: https://www.bing.com/search/BASIC+EMERGENCY+OBSTETRIC+\%26+NEWBORN+CARE+\%28BEmONC\%29+Training+Manual+in+Ethiopia. Acecced, 13 May 2021.

25. United Nations Population Fund. Investing in midwives: stories from Ethiopia. 2014. Avaliable from: https://ethiopia.unfpa.org/sites/default/files/pub-pdf/UNFPA\%20Booklet_Midwifery.pdf. Accessed, 28 Aug 20121.

26. Ethiopian Public Health Institute. Mini Demographic and Health Survey 2019. Addis Ababa, Ethiopia, and Calverton, Maryland, USA. 2019. Avalaible from: Http://www.moh.gov.et/ejcc/sites/default/files/Complete_KIR_EMDHS-20Final.pdf. Accessed, 9 Augest 2020. 
27. Ejigu TT, Afework MF, Yalew AW. Antenatal care service quality increases the odds of utilizing institutional delivery in Bahir Dar city administration, North Western Ethiopia: A prospective follow up study. PLOS ONE. 2018;13(2). https://doi.org/10.1371/journal.pone.

28. Seyoum T, Alemayehu M, Christensson K, Lindgren H. Client Factors Affect Provider Adherence to Guidelines during First Antenatal Care in Public Health Facilities, Ethiopia: A Multi-Center Cross-Sectional Study. Ethiopian Journal of Health Sciences. 2020;30(6).

29. Seyoum TAM, Christensson K, Lindgren H,. Provider-Perceived Benefits and Constraints of Complete Adherence to Antenatal Care Guideline Among Public Health Facilities, Ethiopia: A Qualitative Study. Research Square; 2020. DOI: 10.21203/rs.3.rs-65478/v1.

30. Hiralal K. Dutta's Textbook of Obstetrics Including Perinatology and Contraception:Abdominal examination during antenatal care. Jaypee Brothers Medical; 2013.

31. Muche AA, Olayemi OO, Gete YK. Effects of gestational diabetes mellitus on risk of adverse maternal outcomes: a prospective cohort study in Northwest Ethiopia. BMC Pregnancy Childbirth. 2020;20(1):73.

32. Worku Takele W, Tariku A, Wagnew Shiferaw F, Demsie A, Alemu WG, Zelalem Anlay D. Anemia among women attending antenatal care at the University of Gondar comprehensive specialized referral hospital, Northwest Ethiopia, 2017. Anemia. 2018;2018.

33. Gedefaw L, Ayele A, Asres Y, Mossie A. Anaemia and associated factors among pregnant women attending antenatal care clinic in Walayita Sodo town, Southern Ethiopia. Ethiopian Journal of health sciences. 2015;25(2):155-64.

34. Bekele A, Tilahun M, Mekuria A. Prevalence of anemia and Its associated factors among pregnant women attending antenatal care in health institutions of Arba Minch town, Gamo Gofa Zone, Ethiopia: A Cross-sectional study. Anemia. 2016;2016.

35. Central Statistical Agency. Ethiopia Demographic and Health Survey 2015. 2016;Addis Ababa, Ethiopia, and Calverton, Maryland, USA: Central Statistical Agency and. Macro ORC. 2016. Avaliable: http://www.ethiodemographyandhealth.org/Measure_DHS_Ethiopia2016.pdf. Accessed, 20 March 2021.

36. Villar J, Bergsjø P. Scientific basis for the content of routine antenatal care I. Philosophy, recent studies, and power to eliminate or alleviate adverse maternal outcomes. Acta obstetricia et gynecologica Scandinavica. 1997;76(1):1-14.

37. Payne BA, Hutcheon JA, Ansermino JM, Hall DR, Bhutta ZA, Bhutta SZ, et al. A risk prediction model for the assessment and triage of women with hypertensive disorders of pregnancy in low-resourced settings: the miniPIERS (Pre-eclampsia Integrated Estimate of RiSk) multi-country prospective cohort study. PLoS Med. 2014;11(1):e1001589.

38. Carroli G, Rooney C, Villar J. How effective is antenatal care in preventing maternal mortality and serious morbidity? An overview of the evidence. Paediatric perinatal Epidemiology. 2001;15:1-42.

39. Hijazi A, Al-Kadri AA,HM,. Effect of Antenatal Care On Fetal, Neonatal And Maternal Outcomes: A RetrospectiveCohort Study. The Internet Journal of Gynecology and Obstetrics. 2019; 23(1).

40. World Health Organization. Recommendations for revention and treatment of pre-eclampsia and eclampsia available: http://apps.who.int/iris/bitstream/10665/44703/1/9789241548335_eng.pdf. Accssed,10 April 2021.

41. Ethiopian Federal Ministry of Health. Antenatal Care Module: Providing focused antenatal care. 2010. Avaliable: https://www.open.edu. Accessed, 9 Augest 2020.

42. Jewaro M, Yenus H, Ayanaw Y, Abera B, Derso T. Knowledge of obstetric danger signs and associated factors among mothers in Bahir Dar district, northwest Ethiopia: an institution-based cross-sectional study. Public Health Rev. 2020;41(1):1-10.

\section{Figures}




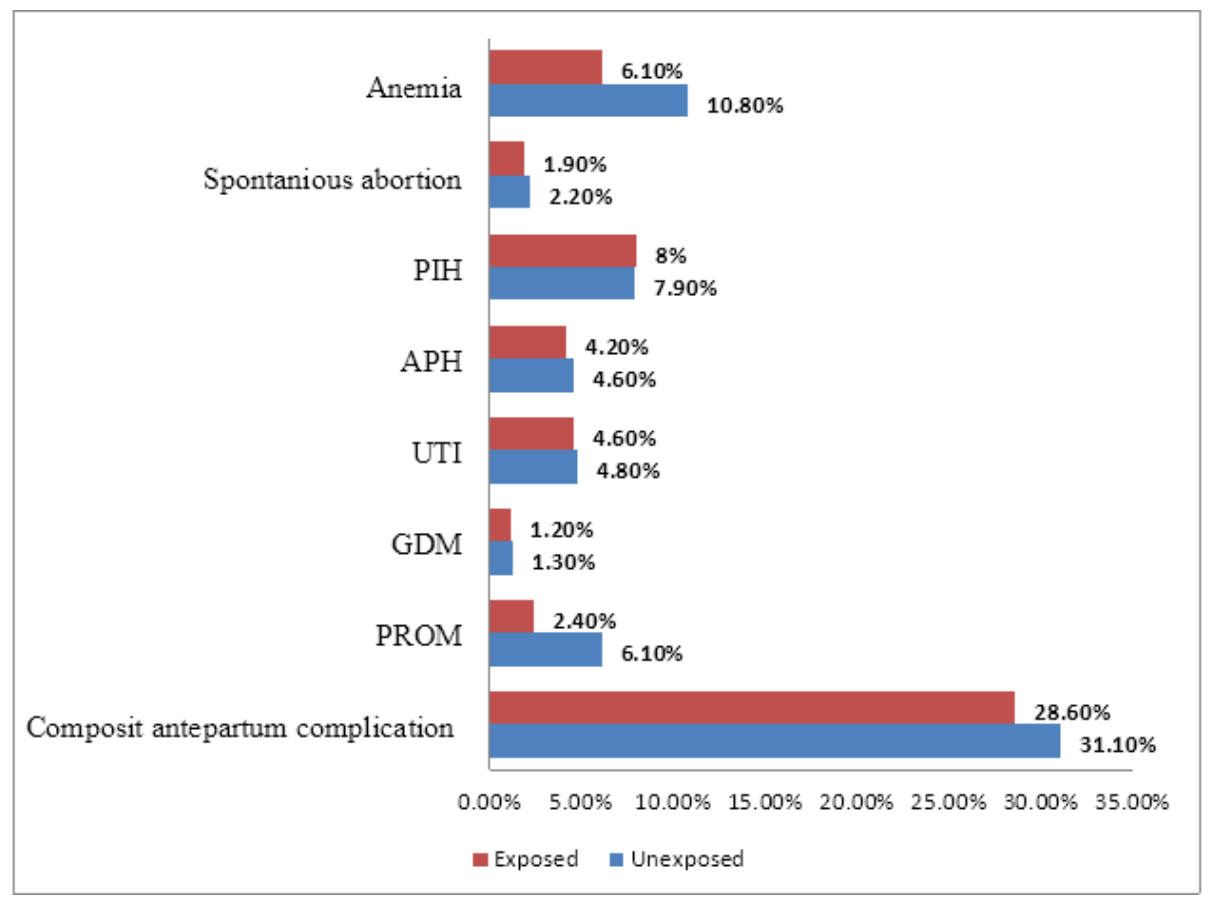

\section{Figure 1}

Incidence of antepartum complications among mothers who received complete and incomplete providers' adherence among women completed the follow up in Gondar town public health facilities, $2020(n=808)$ 